\title{
Chernobyl accident: Causes, consequences and problems of radiation measurements
}

\author{
V. Kortov*, Yu. Ustyantsev \\ Physical \& Engineering Institute, Ural Federal University, 19 Mira Str., 620002 Ekaterinburg, Russia
}

\section{H I G H L I G H T S}

- The short comparative analysis of accidents at Chernobyl and Fukushima is given.

- We note the great effect of $\beta$-radiation on the radiation situation at Chernobyl.

- We discuss the problems of radiation measurements under these conditions.

- The impact of shelter on the radiation situation near Chernobyl NPS is described.

\section{A R T I C L E I N F O}

\section{Article history:}

Received 4 April 2012

Received in revised form

28 May 2012

Accepted 31 May 2012

\section{Keywords:}

Nuclear accident

Radioactivity release

Radioactive contamination

Radiation situation

Mixed radiation

\begin{abstract}
A B S T R A C T
General description of Chernobyl accident is given in the review. The accident causes are briefly described. Special attention is paid to radiation situation after the accident and radiation measurements problems. Some data on Chernobyl disaster are compared with the corresponding data on Fukushima accident. It is noted that Chernobyl and Fukushima lessons should be taken into account while developing further measures on raising nuclear industry safety.
\end{abstract}

(c) 2012 Elsevier Ltd. All rights reserved.

\section{Introduction}

During the lifetime of one generation there were 4 major radiation accidents with area contamination in different countries:

- at the atomic plant "Mayak", USSR, 1957;

- at nuclear power station (NPS) "Three Mile Island", USA, 1979;

- at Chernobyl NPS, USSR, 1986;

- at NPS “Fukushima”, Japan, 2011.

Fukushima-Daiichi nuclear accident (March, 2011) occurred during preparation for the 25th anniversary of Chernobyl disaster. The International Conference devoted to this event took place in April 2011. Ukraine national report entitled "25 Years after Chernobyl Accident. Safety for the Future" (Baloga, 2011) was prepared. It considered radio-ecological, radiological, medical, socioeconomic

\footnotetext{
* Corresponding author. Tel.: +7 34337544 43; fax: +7 3433754415 . E-mail address: vskortov@mail.ru (V. Kortov).
}

and social-psychological consequences of the Chernobyl accident given post-accident period. It was of special interest for the specialists to compare both accidents and make an attempt to use the Chernobyl lessons to liquidate the consequences in Fukushima.

This paper is based on the authors' invited report made at Fukushima Session of the 7th International Workshop on Ionizing Radiation Monitoring (December 3-4, 2011, Oarai, Japan). It presents brief analysis of the causes, consequences and problems of radiation measurements in the radiation situation which occurred after Chernobyl nuclear accident. Published materials as well as personal experience of one of the authors (V. Kortov) being a participant of the Chernobyl accident elimination (July-September, 1986) as the head of the dosimetric team monitoring contaminated areas near the destroyed reactor are used.

\section{Causes of Chernobyl nuclear accident}

The reactor explosion in the 4th Unit of Chernobyl NPS was caused by design flaws and staff operation errors (Porfiriev, 1996; Gorbachev and Solomonov, 2006; Baloga, 2011). 
The main drawbacks of RBMK-1000 reactor were reactivity increase resulting from insertion of control and protection rods into the reactor core and low speed of reactor protection system operation. Emergency protection rods were inserted into the reactor within $18 \mathrm{~s}$ (instead of 2-3 s) which prevented the control and protection system from effective control over fast processes in the reactor.

The accident occurred during the scheduled tests of power supply mode in case of external sources loss. This mode was conceived in the test program and was to be launched if the reactor capacity dropped by $30 \%$ accompanied by emergency cooling system shut down. In this term there is some similarity with Fukushima accident, when the emergency cooling systems were destroyed by the earthquake and tsunami. The Fukushima reactors, however, were shut down immediately after the first shook of the earthquake. The Chernobyl staff in absence of the emergency cooling lowered the reactor capacity down to inadmissible low level (20\% from the nominal capacity). Constructional and physical characteristics of RBMK-1000 reactor did not allow the staff to effectively control its work at such low capacity. However, (Summary Report, 1986) the scheduled tests were completed and the staff received the command to shut down the reactor. It was this scheduled procedure that appeared to be the accident cause. The insertion of the protection rods into the reactor core at low reactivity level did not bring the reactor to a halt. On the contrary, it led to sharp increase in reactivity, reactor power growth and fast heating of the reactor active zone which caused the explosion. The photo picture of the explosion destroyed part of the reactor core and reactor building at Chernobyl is shown in Fig. 1.

\section{Radiation situation and problems of radiation measurements}

Explosions and ejection of radioactive substances and fire lasted for 10 days. The active zone of reactor was damaged and nuclear fuel was melted as shown in Fig. 2. 70 tons of nuclear fuel was ejected by the exploded reactor. Another 50 tons of nuclear fuel and 800 tons of graphite burned down in the destroyed reactor.

The exploded reactor created the dose level of $\gamma$-radiation about $300 \mathrm{~Sv} / \mathrm{h}$ (Tarasenko, 2011).

The dose rate within 10 days (6th May 1986) after the accident was the following:

- at distance of $150 \mathrm{~m}$ away from the reactor - $12 \mathrm{~Gy} / \mathrm{h}$;

- in Pripyat ${ }^{1}-10 \mathrm{mGy} / \mathrm{h}$ (air), on roads - asphalt up to $600 \mathrm{mGy} /$

h, soil up to $200 \mathrm{mGy} / \mathrm{h}$.

Three months later (26th July 1986) the dose rate at distance of $150 \mathrm{~m}$ away from the ruins of the 4th Unit of Chernobyl NPS was more than $3 \mathrm{~Gy} / \mathrm{h}$.

Near the reactor and within the $30 \mathrm{~km}$ zone away from it the maximum dose rate for liquidators' work and staying was $250 \mathrm{mGy} / \mathrm{h}$ and the everyday dose rate had to be less than $20 \mathrm{mGy} /$ h.

The part of the reactor core which was ejected by explosion had formed a radioactive cloud which moved at heights from one to $11 \mathrm{~km}$ (Medvedev, 1989). The cloud was moving to north-west across Belarus and Baltic states crossing the USSR's borders.

Huge territories of former USSR with a population of 945,000 people were polluted.

\footnotetext{
1 Pripyat was the town of about 50,000 people near Chernobyl NPS, in which the staff of station, builders and workers of service centers lived.
}

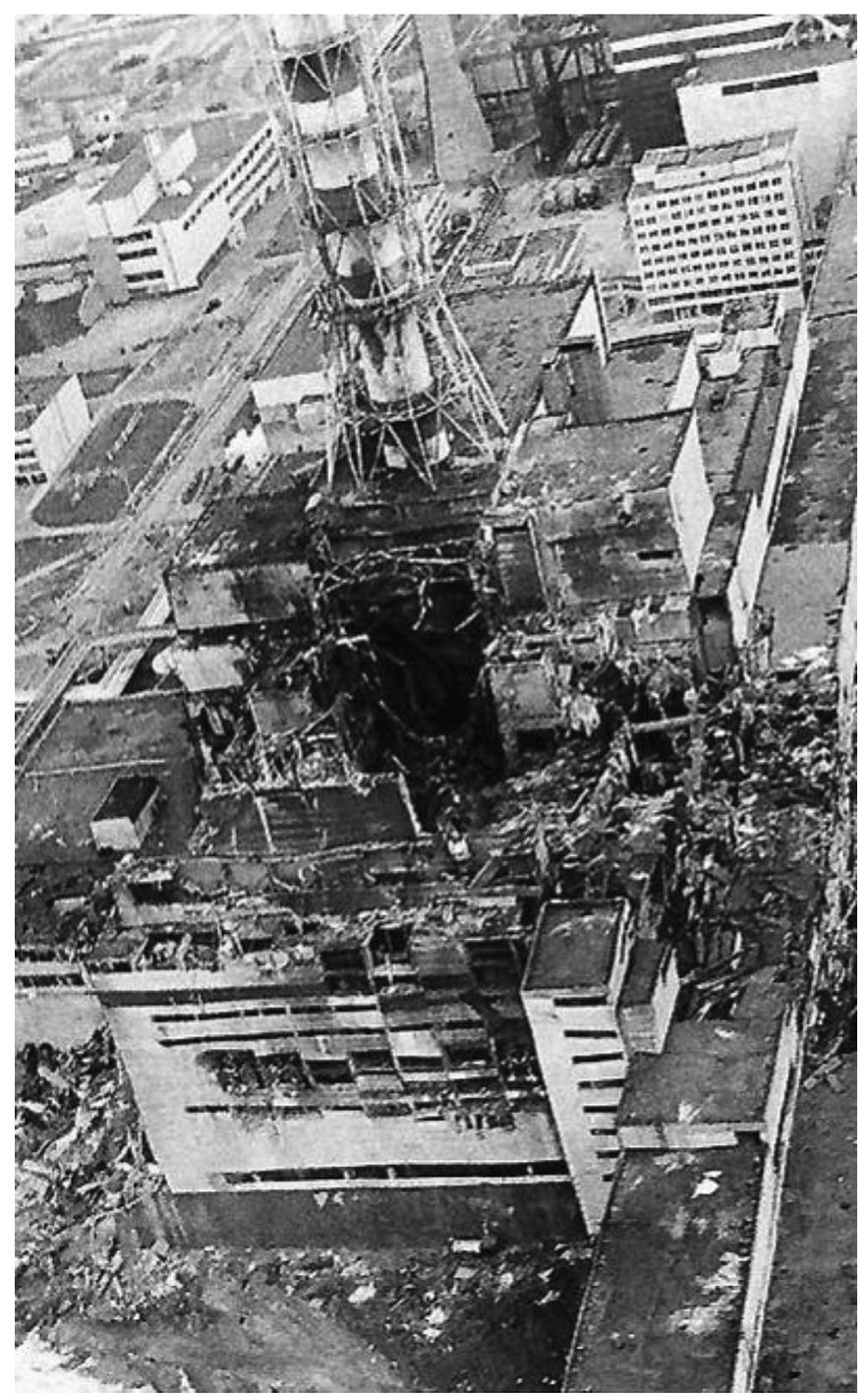

Fig. 1. Photo of the destroyed reactor at Chernobyl NPS.

Falls from contaminated clouds caused the appearance of zones with excessive radioactive pollution in Sweden, Finland, Germany, Austria, Switzerland and other countries. Many people who lived in cities Pripyat, Chernobyl and other settlements $20-30 \mathrm{~km}$ from Chernobyl NPS were evacuated (Abogjan et al., 1986).

Let us consider the problems of radiation measurements in the radiation situation mentioned above.

\subsection{Absence of necessary equipment}

There was no supposition that for reactors of RBMK-1000 type such large-scale accident with a complete destruction of the core was possible. For this reason there was no necessary dosimetric and radiometric equipment allowing to estimate radiation situation near the reactor immediately after the accident under conditions of high dose rate. It led to the late assessment of the accident scale. It also was the cause of absence of the necessary protective outfit for the firemen working on the 4th Unit. As a result, many of them died from the acute radiation disease (Baloga, 2011).

After the reactor explosion radioactive nuclides were forming very violent fields of mixed $\alpha+\beta+\gamma$ radiation. There was no control equipment able to measure mixed radiation. 


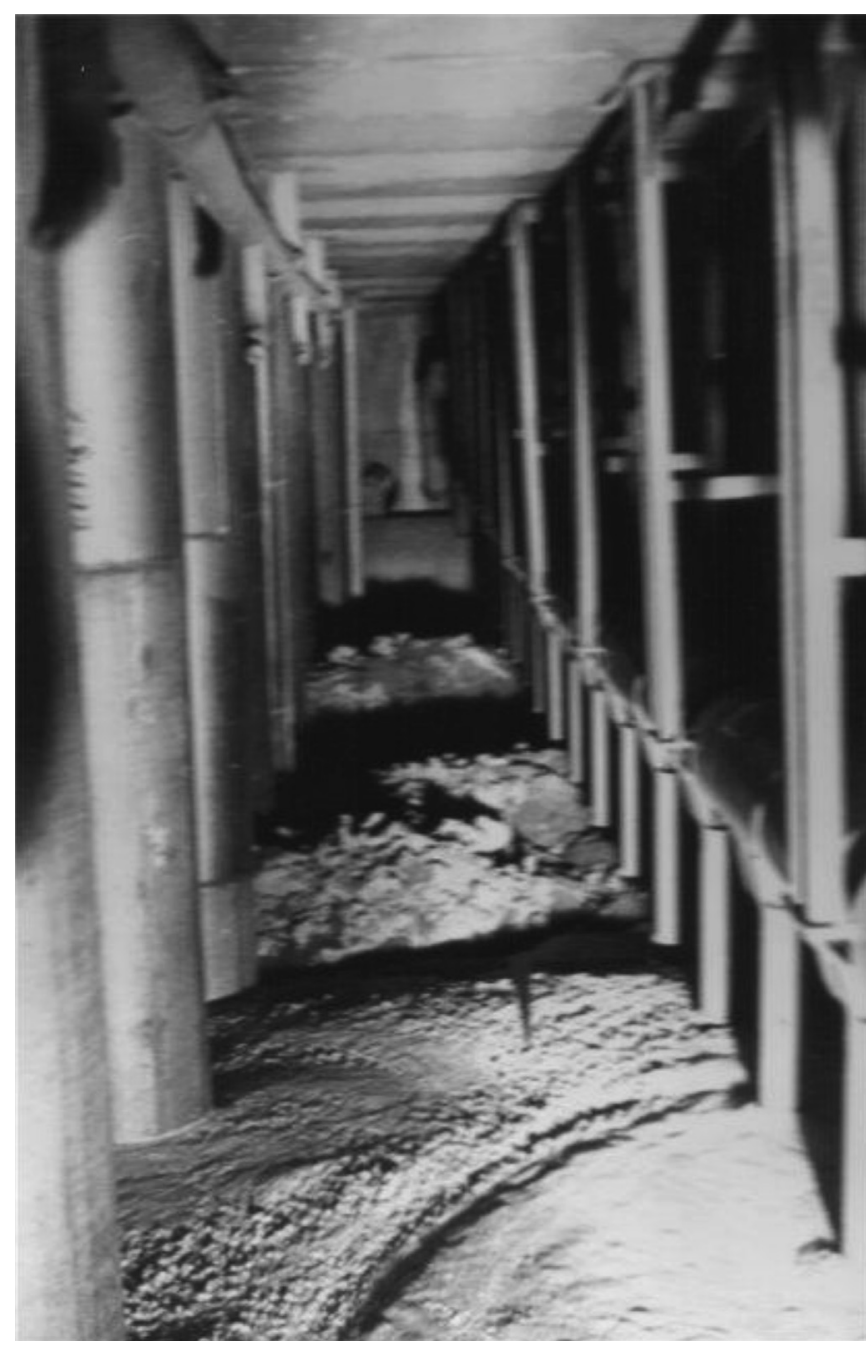

Fig. 2. Floats of fuel-containing substances under reactor.

\subsection{Different sensitivity of detectors to $\beta$-radiation}

During the liquidation of the accident's consequences at the Chernobyl NPS various detectors were used: ionized chambers, gasdischarge counters and TLDs (Table 1). This detectors had different thickness and density of casing. Therefore they had different sensitivity degrees to $\beta$-radiation (Tarasenko, 2011).

\subsection{Big diversity of measured data}

The comparison of the registered data in the same place of Chernobyl area shows that under the high-intensity $\beta$-radiation there was a big diversity of measured values obtained from

Table 1

Some types of dosimeters and detectors used after Chernobyl accident.

\begin{tabular}{lll}
\hline Type of dosimeter & Detector & Dose range \\
\hline DR-5M & Gas-discharge counter & $0-2 \mathrm{~Gy} / \mathrm{h}$ \\
ID-11 & RP & $0-15 \mathrm{~Gy} / \mathrm{h}$ \\
Victoreen-541L & Ionized chamber & $0-2 \mathrm{mGy}$ \\
KDT-02 & TLD-400 & $0.1-10 \mathrm{~Gy}$ \\
DP-22B & Ionized chamber & $0-0.5 \mathrm{~Gy}$ \\
ID-1 & Ionized chamber & $0-5 \mathrm{mGy}$ \\
Victoreen-47A & Ionized chamber & $0-10 \mathrm{~Gy} / \mathrm{h}$ \\
\hline
\end{tabular}

Table 2

Diversity of data registered by means of different types of dosimeters in the same place of Chernobyl area.

\begin{tabular}{lll}
\hline Type of dosimeter & $\begin{array}{l}\text { Number of } \\
\text { dosimeters }\end{array}$ & $\begin{array}{l}\text { Registered data } \\
(\mathrm{mGy} / \mathrm{h})\end{array}$ \\
\hline ID-02 & 4 & 2.57 \\
DK-02 & 4 & 2.34 \\
Victoreen-541L (USA) & 5 & 1.68 \\
Clinical dosimeter 27012 (DDR) & 1 & 4.49 \\
DP-5W & 1 & 0.85 \\
\hline
\end{tabular}

different detectors because of the variation in casing thickness and density as listed in Table 2 .

The difference of the registered data can mount to $300 \%$. Special measures were needed to calibrate the dosimetric instruments.

\subsection{Complicated composition of isotopes}

A mixture of radioactive sources created by various isotopes accounted for a radiation level in area of Chernobyl NPS as listed in Table 3. This table shows the measurements data of spectrum analyses of soil sample (01.08.1986). One can see that many radionuclides formed during and after the accident. The isotopic composition varied with time.

According to the calculations made, contribution of betaradiation to the readings of dosimeters with radiation case thickness of $0.3-0.625 \mathrm{~g} / \mathrm{cm}^{3}$ depending on the post-accident time period can change 20-60-fold due to the isotopic composition of radionuclides (Tarasenko, 2011). Moreover, as time passes contribution of $\beta$-particles with energy less than $0.5 \mathrm{MeV}$ to the absorbed dose increases.

\subsection{Change of $\beta$-radiation contribution to radiation status}

An increase of contribution ratio of $\gamma+\beta$ radiation to $\gamma$-radiation was observed during the long (about a year) period, due to changes of radioactive nuclides composition because of the short-lived isotopes break-up (Fig. 3). That caused a rise of $\beta$-radiation part in mixed $\gamma+\beta$ radiation fields.

It was found that due to the high contribution of $\beta$-radiation radiological exposure on the accident liquidators' skin was tens and hundreds times higher than radiation exposure of other parts of human body. Regarding this, in the work (Tarasenko, 2011) it is offered to ban the usage of the means measuring exposure dose and dose rate under conditions of mixed ionizing radiation effect after accidents.

Table 3

Isotopic composition of soil sample at distance of $3 \mathrm{~km}$ from the destroyed reactor.

\begin{tabular}{ll}
\hline Radionuclides & Activity $\mathrm{A}_{\mathrm{T}} \mathrm{Bq} / \mathrm{kg}$ \\
\hline${ }^{141} \mathrm{Ce}_{58}$ & $0.45 \cdot 10^{5}$ \\
${ }^{131} \mathrm{I}_{53}$ & $0.43 \cdot 10^{2}$ \\
${ }^{103} \mathrm{Pu}_{44}$ & $0.52 \cdot 10^{5}$ \\
${ }^{106} \mathrm{Ru}_{44}$ & $0.57 \cdot 10^{5}$ \\
${ }^{134} \mathrm{CS}_{55}$ & $0.7 \cdot 10^{4}$ \\
${ }^{137} \mathrm{CS}_{55}$ & $0.15 \cdot 10^{5}$ \\
${ }^{95} \mathrm{Zr}_{40}$ & $0.13 \cdot 10^{6}$ \\
${ }^{140} \mathrm{Ba}_{56}$ & $0.17 \cdot 10^{4}$ \\
${ }^{144} \mathrm{Ce}_{58}$ & $0.19 \cdot 10^{6}$ \\
${ }^{103 m} \mathrm{Rh}_{45}$ & $0.52 \cdot 10^{5}$ \\
${ }^{144} \mathrm{Pr}_{59}$ & $0.19 \cdot 10^{6}$ \\
${ }^{140} \mathrm{La}_{57}$ & $0.19 \cdot 10^{4}$ \\
${ }^{95} \mathrm{Nb}_{41}$ & $0.22 \cdot 10^{6}$ \\
${ }^{\mathrm{In} \mathrm{all}}, \mathrm{A}_{\mathrm{T}}$ & $0.10 \cdot 10^{7}$ \\
\hline
\end{tabular}




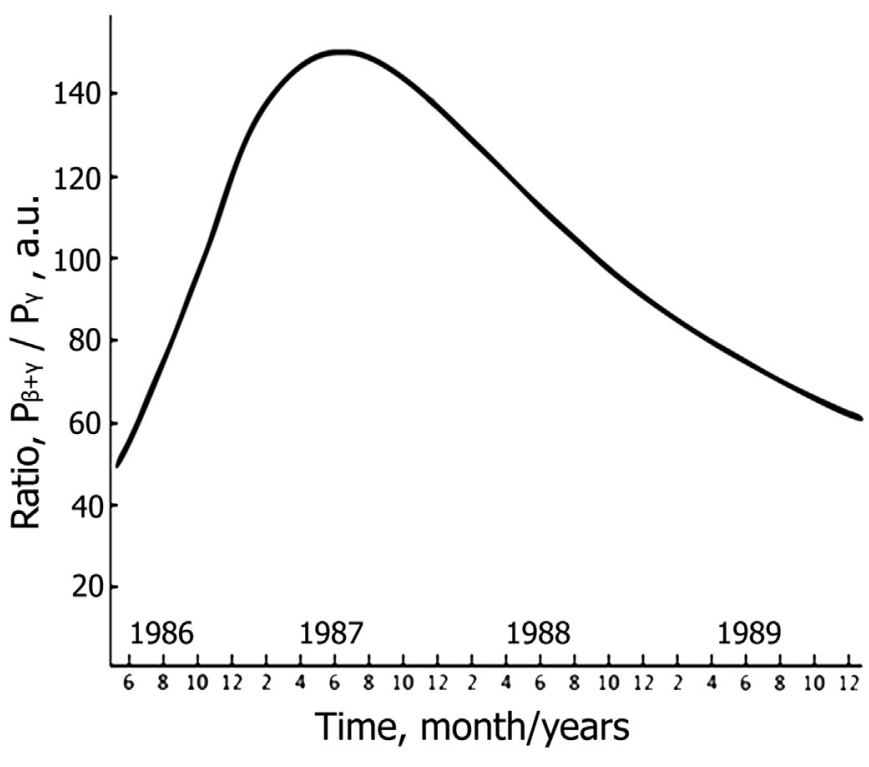

Fig. 3. Dependence of ratio $P_{\gamma+\beta} / P_{\gamma}$ on time after Chernobyl accident.

\section{Comparison of the accidents at Chernobyl and Fukushima}

First of all, it should be noted that the accidents at Chernobyl and Fukushima have different causes. The causes of the accident at Chernobyl NPS are described above. The accident at the Fukushima NPS is due to loss of cooling reactors and ponds for spent nuclear fuel (Strishov, 2011). The earthquake destroyed the system of stationary power supplies of NPS. Giant tsunami damaged the emergency power supply located near the ocean. A large amount of steam was created under conditions of insufficient cooling of the reactors. The interaction of steam with parts of the reactors containing zirconium led to the formation of a hydrogen and oxygen mixture and its explosion. Explosions and fires destroyed the upper part of the reactors buildings, there was a release of radioactive substances into the atmosphere (Chernikov, 2011; Machi, 2012).

The composition of radioactive releases was also different. The accident at the Chernobyl NPS was accompanied by the release of irradiated nuclear fuel solid particles and fission products ("hot" particles) with different isotopic composition. The accident at the Fukushima NPS was accompanied largely by the release of volatile isotopes, in particular, isotopes of iodine and cesium (Chernikov, 2011 ). Effect of $\beta$ and $\alpha$-radiation on the radiation situation was not so strong compared to the accident at Chernobyl.

The consequences of accidents at Chernobyl and Fukushima can be compared on the following indices (Israel et al., 1990; Machi, 2012):

1. Release of radioactive substances into the atmosphere: $5.2 \cdot 10^{18} \mathrm{~Bq}$ (Chernobyl) and $6.3 \cdot 10^{17} \mathrm{~Bq}$ (Fukushima).

2. Contamination of the territories of their countries: $450,000 \mathrm{~km}^{2}$ (Chernobyl) and $8000 \mathrm{~km}^{2}$ (Fukushima).

3. Contamination of the territory of other countries: $250,000 \mathrm{~km}^{2}$ in Western Europe (Chernobyl). The accident at the Fukushima NPS did not cause pollution in other countries.

4. The area of evacuation: $10,800 \mathrm{~km}^{2}$ (Chernobyl) and $1100 \mathrm{~km}^{2}$ (Fukushima).

- Evacuation of the population: 400,000 people (Chernobyl) and 83,000 (Fukushima).

- Loss of lives from the acute radiation disease within 4 months after the accident: 28 (Chernobyl) and 0 (Fukushima).
The above brief comparison shows that the scale of the accident at the Chernobyl NPS is about 10 times greater than the scale of the accident at the Fukushima NPS (Machi, 2012). The accident at the Chernobyl NPS was international disaster with pollution in other countries. The pollution at the Fukushima NPS accident is limited to the areas within Japan.

Note also that the release of radioactive substances and radiation situation in the polluted areas within $30 \mathrm{~km}$ zone of Chernobyl NPS caused grave consequences for the health of the liquidators. The results of exposure to $\beta$-radiation were: "nuclear sunburn" skin blackening of faces and hands of the first liquidators and "nuclear quinsy" - continuous hoarse cough due to throat and bronchia burn (Medvedev, 1989; Tarasenko, 2011)

\section{Main measures for the liquidation of accident consequences at Chernobyl NPS}

More than 15,000 tons of different materials (lead, carbide of boron, dolomite, sand, etc) were dropped from helicopters in the destroyed reactor for prevention of nuclear reaction and localization of ejecting sources of radioactive substances.

The sarcophagus (shelter) was built within the extremely short time ( 6 months) in the conditions of high level radiation. Wide complex of works on the decontamination of NPS territory and the surrounding area was carried out. After decontamination a part of forests and agricultural lands is suitable for use. Enormous measures were taken for the decontamination of water sources and for supply of population with clean water. Social protection for liquidators and people who lived in contaminated areas was provided, and regular monitoring of their health was organized.

Unfortunately, the territory of Chernobyl NPS, the cities Pripyat, Chernobyl and the surrounding area within $30 \mathrm{~km}$ zone have been closed over a long period of time. Pripyat is now a ghost city. The streets are overgrown with trees, buildings are destroyed.

There are the problems of shelter (Fig. 4). The shelter erection was an important event in stabilization of radiation situation near the destroyed reactor. The shelter however was not able to solve a set of problems connected with the ecologically safe system of environmental protection from the radioactive pollution caused by destroyed reactor.

According to the calculated data, inside the shelter there is still about 95\% of the irradiated nuclear fuel (Krupny, 1996). It is found in the fragments of the reactor core, in the fuel dust and in the lava materials. Total activity of radionuclides inside the shelter at present is about $4.8 \cdot 10^{17} \mathrm{~Bq}$ (Baloga, 2011). Radiation hazard is presented by aerosols responsible for air pollution inside as well as outside the shelter. There are still rooms inside the shelter where expose dose rate is over $10 \mathrm{~Gy} / \mathrm{h}$, though in most rooms it does not exceed $10 \mathrm{mGy} / \mathrm{h}$. Some aerosols leak through crevices and technical hatches in the shelter forming "unexpected" radioactivity release. As a result, expose dose rate $150 \mathrm{~m}$ from the shelter is about $0.15 \mathrm{mGy} / \mathrm{h}$ (detected by V. Kortov 26.04.2011) which is 1000 times as much as natural background.

The tons of radioactive dust accumulated inside the shelter not only pollute the environment, but are also the source of potential danger. The dust atmosphere with particles of the submicrometer size behaves like liquid in which heavier particles (Pu-239, Pu-241, $\mathrm{U}-235$ ) precipitate in the lower rooms of the shelter. As a result high concentrations of fissionable nuclear materials can form spontaneously, which can cause explosion. Such example with radioactive waste explosion at the nuclear enterprise "Mayak" (USSR, 1957) is known. Regarding this, confinement over the shelter is planned to be constructed in the near future, which is of great value and will help to reduce the danger. However, the main function of the 


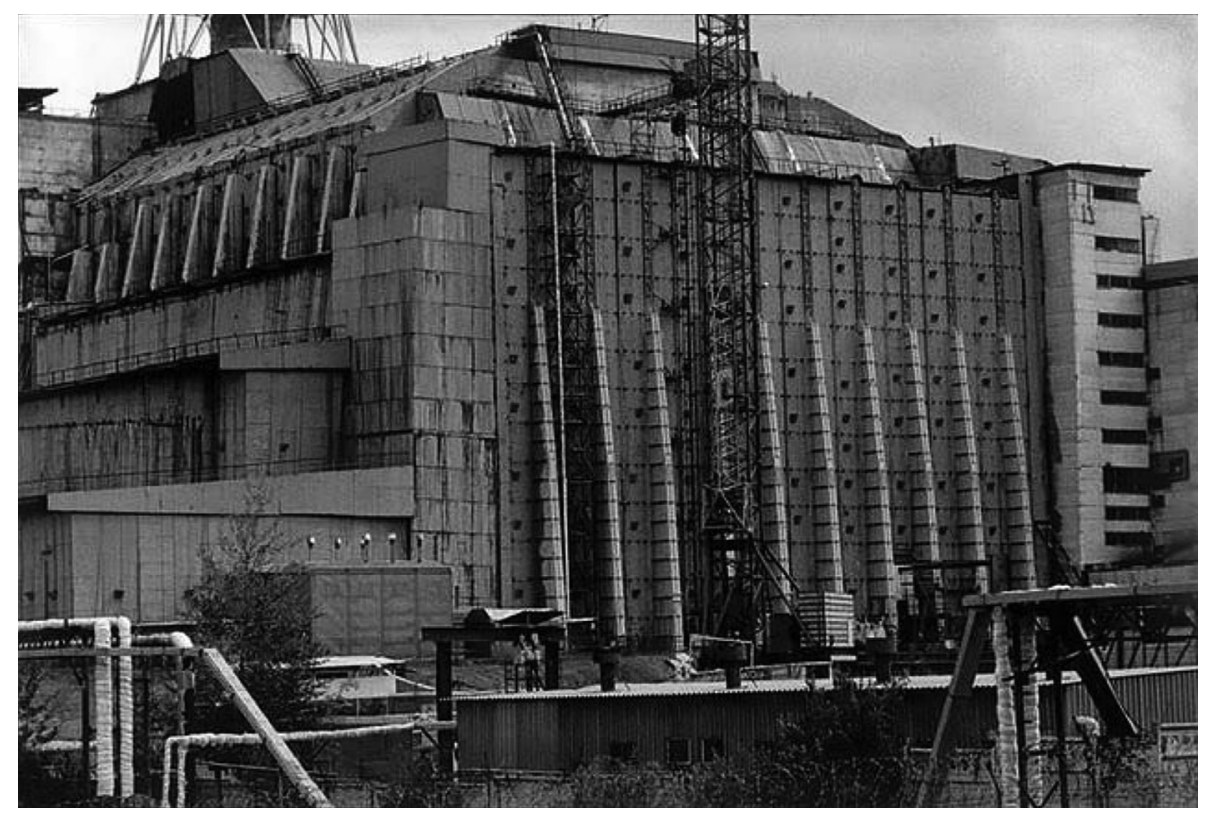

Fig. 4. Photo of Chernobyl reactor shelter (April, 2011).

confinement is to provide conditions for disposal of radioactive and fissionable materials from the 4th Unit of the Chernobyl NPS.

As is known, at present the construction of the shelter over the destroyed reactor unit $\mathcal{N} \circ 1$ in Fukushima NPS is being completed (Machi, 2012). Hopefully, the experience of shelter construction for Unit $\mathcal{N} \circ 4$ of the Chernobyl NPS will be taken into account by the Japanese specialists who are to clear the destroyed reactor from the fissionable materials and radioactive fragments of the reactor core within the shortest time possible.

\section{Conclusion}

The operators working with RBMK-1000 reactor were not informed of its flaws. The process operator guide and work manual did not contain information on the reactor operation restrictions. This situation was due to the secrecy order of the Soviet nuclear science and industry. The latter was completely concealed from the international and national public control. Such isolation led to the weakness of the Soviet nuclear industry in a number of significant radiation safety issues, and to the absence of what is called "safety culture" (Baloga, 2011).

The Chernobyl accident was a hard blow to the NPS prestige and slowed down its development significantly.

Consequences of major NPS accidents can be much more than a national problem and may cause global catastrophe. The accident is accompanied by many consequences which require a long time and enormous financial resources to liquidate them.

The Chernobyl accident has shown that a creation and maintaining of an effective emergency system for personnel and technical departments of NPS and, especially, for dosimetric departments are necessary. Reliable and timely information allows to take actions needed to minimize the consequences of accidents and protect people from irradiation.

Modern society is not able to refuse nuclear power use. The Chernobyl memories oblige people to be responsible for and careful in hazardous technologies usage. It is impossible to use nuclear power without scientific and technological support, highlyqualified staff training system, multilevel system of responsibilities and decision-making, safety culture development.

\section{References}

Abogjan, A., Asmolov, V., Guskova, A., 1986. Chernobyl accident and its consequences. Atomic Energy 61 (5), 301-320 (Report for IAEA).

Baloga, V. (Ed.), 2011. Twenty Five Years after Chernobyl Accident. Safety for Future. National Report of Ukraine, Kiev.

Chernikov, O., 2011. Competent evaluation. Rusenergyatom 5, 18-21.

Gorbachev, B., Solomonov, Yu, 2006. Chernobyl accident: evolution of view on circumstances and causes. ANRI 2, 11-18.

Israel, Yu, Vakulovsky, S., Vetrov, V., Petrov, V., Rovinsky, F., Stukin, E., 1990. Chernobyl: Radioactive Contaminations of Environment (Moscow).

Krupny, V., 1996. Object "Shelter": Yesterday, Today, Tomorrow (Kiev).

Machi, S., 2012, Proc. 7th Internat. Workshop on Ionizing Radiation Monitoring, Fukuhsima Session, 49-61, December 3-4, Orai, Japan.

Medvedev, G., 1989. Current Events of Chernobyl (Moscow).

Porfiriev, B., 1996. Chernobyl: causes, evaluations, consequences, nuclear encyclopedia, Moscow.

Strishov, V., 2011. The Fukushima situation under control. Rusenergyatom 5, 23-25.

Summary Report on the post-accident: review on the Chernobyl accident, 1986. Safety Series No. 75-INSAG-1. IAEA, Vienna.

Tarasenko, Yu, 2011. The Ash of Chernobyl (Moscow). 